\title{
Analytical Model for the Estimation of Leak Location in Natural Gas Pipeline
}

\author{
Obibuike Ubanozie Julian, Ekwueme Stanley Toochukwu*, Ohia Nnaemeka Princewill, \\ Igwilo Kevin Chinwuba, Onyejekwe Ifeanyi Michael, Igbojionu Anthony Chemazu
}

Department of Petroleum Engineering, Federal University of Technology, Owerri (FUTO), Nigeria

\author{
Email address: \\ stanleyekwueme $($ y)yahoo.com (S. T. Ekwueme) \\ ${ }^{*}$ Corresponding author
}

\section{To cite this article:}

Obibuike Ubanozie Julian, Ekwueme Stanley Toochukwu, Ohia Nnaemeka Princewill, Igwilo Kevin Chinwuba, Onyejekwe Ifeanyi Michael, Igbojionu Anthony Chemazu. Analytical Model for the Estimation of Leak Location in Natural Gas Pipeline. International Journal of Oil, Gas and Coal Engineering. Vol. 7, No. 4, 2019, pp. 95-102. doi: 10.11648/j.ogce.20190704.12

Received: September 28, 2019; Accepted: October 23, 2019; Published: November 11, 2019

\begin{abstract}
Mathematical model for leak location in natural gas pipeline has been developed in this paper. The model employs an isothermal steady state approach. Leak occurrence in the pipeline divides the pipeline into two sections-the upstream and downstream sections respectively. Analyses of leak incidences were carried out in the two pipeline sections giving rise to two equations being developed to address the leak localization. The first leak equation was developed by considering the upstream section of the pipeline while the second leak equation was developed by considering the downstream section of the pipeline. The two equations were analytically developed by slight modification of the Weymouth's equation for gas flow in horizontal pipeline. Matlab software was used in the model simulation. Seven field data were used in the model simulation. The results from the Matlab simulation of the mathematical models developed gave the leak locations for each of the field cases. Comparison of the simulated results with actual results of leak locations determined experimentally revealed high level of accuracy with an average error of only $0.377 \%$ which is below the minimum acceptable limit. Furthermore analyses of results show that the two leak equations yield same results when used in the Matlab simulator. The model is highly suitable for accurate detection of leak in natural gas pipeline especially where economics and reliability is of essence.
\end{abstract}

Keywords: Leak Location, Mathematical Model, Upstream Section, Downstream Section

\section{Introduction}

Pipelines provide the most efficient means of transporting hydrocarbon fluids from one place to another. Pipelines provide better efficiency in fluid transportation when compared to trucks, rail or marine transportation. However, leaks, which are the main faults of gas pipelines, can cause serious problems related not only to the environment but also to economy. A leak detection system is a safety and integritycritical component of an operating pipeline that is designed to help mitigate negative consequences following a leak occurrence in a pipeline $[1,2]$.

The methods for leak detection fall into two broad categories; these are externally (released fluid detection) and internally (observing hydraulic behavior) based methods. The externally based methods are also referred to as physical inspection methods and is done to identify the locations and sizes of leaks. Physical inspection consists of gas sampling; soil monitoring; flow-rate monitoring; and acoustic-, optical-, and satellite-based hyper spectral imaging. Usually, the physical inspection can result in an accurate detection of the location and size of a leak, but this comes with the expense of production shutdown and the high cost/long time to run the physical detection, which is very crucial in a longdistance gas pipeline.

The internal methods fall into a broad category referred to as model based leak detection methods. These models are mathematical equations analytically or numerically developed to address leak phenomena in pipelines. Model based methods continually measure pressure and/or mass flow signals frequently at the intake and outtake of the pipeline [3, 4]. This Mathematical-modeling approach detects a gas leak by solving the governing mass-conservation, 
momentum-conservation, and energy- balance equations, thus leading to a quick evaluation of leak at a much lower cost. It also has the advantages of monitoring the system continuously and noninterference with pipeline operations. One of the limitations of the modeling method is that it requires flow parameters, which are not always available. Leak detection from mathematical modeling also has a higher uncertainty than that from physical inspection.

This paper presents a mathematical model to estimate leak location in a natural gas pipeline. The approach is based on the mass balance and pressure point analyses in the pipeline.

Many researchers have conducted investigations on gas transient flow in pipelines to detect leaks.

Reddy et al. [5] built a dynamic simulation model by use of a transfer-function model for online state estimation and leak detection in a gas pipeline. The model reduced the computational time, while obtaining accurate state estimation from noisy measurements. The computation required all available measurements of pressure and flow rate.

Wang and Carroll [6] analyzed the real-time data with a transient model to detect gas- and liquid-pipeline leakage. Stochastic processing and noise filtering of the meter reading were used to reduce the impact of noise. The correlations for diagnosing the leak location and amount are derived on the basis of the online real-time observation and the readings of pressure, temperature, and flow rate at both ends of the pipeline.

Gajbhiye and Kam [7] used a mechanism model to detect leakage in a subsea pipeline under fixed pressure boundaries. The model compared the inlet and outlet flowrate changes with fixed-pressure boundary conditions to detect leakage. Although the model can be applied to single- and multiphase flows, it needed pressures and flow rates at both ends of the line. Elliott et al. [8] showed the efficiency of leak detection by a spherical acoustic device called a SmartBall ${ }^{\circledR}$, which has the advantages of low cost, ease of deployment, and the ability to locate pinhole leaks immediately to within $1 \mathrm{~m}$. This technique is limited by pipeline geometry. A long pipeline also requires long inspection time to detect leakage. Launching and receiving SmartBalls are necessary, which may not be applicable in some conditions. Hauge et al [9] used an adaptive Luenberger-type estimator to locate and quantify leakage given inlet velocity, pressure, and temperature and outlet velocity and pressure. The model was built in OLGA, a commercial software from Schlumberger [10], which can handle multiphase flow and incorporated temperature dynamics. Pressure and rate at two ends of the pipeline are required for numerical calculation. Ben-Mansouri [11] developed a $3 \mathrm{D}$ turbulent flow model with $10 \mathrm{~cm}$ diameter pipeline to detect small leakage in water distribution pipeline. He made use of Quadropole simulation methods leading to a much complex treatment of the leak phenomena. Balda Rivas and Civan [12] used mass-balance and transient flow models to detect leaks in liquid pipelines. The response times to the transient-flow operation were used to estimate leak location. Their model required intensive measurements of all variables. Zhou et al [13] developed a numerical model to simulate fluid leakage from damaged submarine pipeline. In his study, the effects of oil properties, leak rate and leak sizes were examined. Hanmer et al [14] modeled transients in natural gas pipeline. He tried to optimize automatic shutdown in gas pipeline. He discovered that the influence of negative pressure wave is more complex for gas pipeline and is affected by the frictional pressure of the pipeline.

In summary, existing methods are classified into two larger categories: physical method and mathematical model. Physical detection has the advantages of accuracy and high certainty. The online, real-time surveillance of pipelines and leak detection can be realized if monitoring equipment is installed in the pipeline. Because the physical method requires installation and maintenance of substantial levels of costly equipment on the pipeline, it may be excluded because the high operating cost is not affordable and the long time taken to detect the leak is unacceptable because of the continuous loss of revenue, damage to facilities and environment, and possible loss of life. Sometimes, a harsh environment or severe weather can make the installation of detection instruments in the pipeline and/or physical inspections impossible. In some cases, remote locations that are difficult to access make physical inspection unrealistic. The mathematical model has the advantages of low cost and quick leak detection.

Shutdown of the operation may not be required. The continuous online, real-time monitoring of the pipeline and leak identification are possible if the required data can be measured and transmitted to the central office simultaneously. The disadvantages of the mathematical model are low accuracy and high uncertainty. High-quality and complete data sets are key factors of detecting leaks successfully [15]. In practice, the mathematical model can be used to narrow down the possible leak interval before the physical inspection is conducted.

\section{Methods}

Natural gas modelling is the representation of gas behaviour by mathematical equation. This enables prediction of behaviour at various conditions. In this case, mathematical equations are used to represent the flow behavior of natural gas as it flows in pipelines. The following assumptions were considered during the modelling.

i. The flow is in steady state regime.

ii. The fluid is in gaseous phase and no phase changes during flow.

iii. The fluid is in single phase throughout the entire flow period.

iv. The effect of environment does not affect pipeline temperature.

$\mathrm{v}$. The pipeline is horizontal and as such effect of elevation is negligible. 


\subsection{Basic Equations of Compressible Fluid Flow}

The basic equations of compressible fluid flow are: Continuity equations, Momentum equations, Energy equations and Equations of state.

For this work the continuity equation shall be the governing equation for the determination of mathematical models that predict natural gas flow behaviour in pipeline both in the leak and the no leak cases.

Consider a fluid element in a pipe of uniform crosssection.

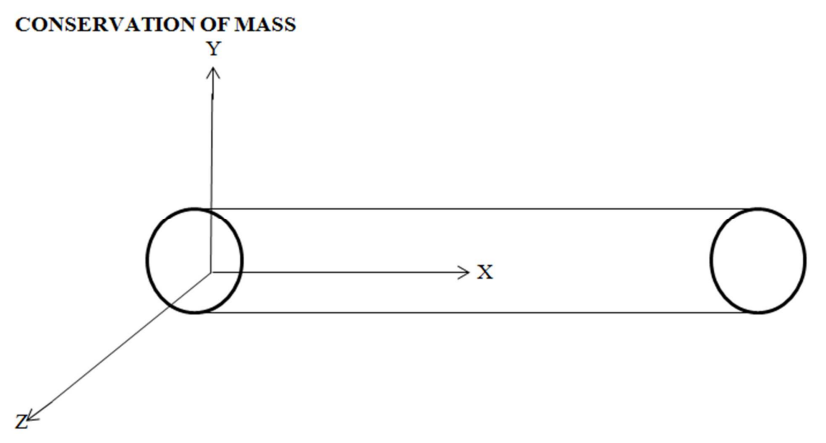

Figure 1. 3-D Pipeline schematics.

From continuity equation in 3 dimension according to figure 1 above,

$$
\frac{\partial}{\partial x}\left(\rho U_{x}\right)+\frac{\partial}{\partial y}\left(\rho U_{y}\right)+\frac{\partial}{\partial z}\left(\rho U_{z}\right)+\frac{\partial}{\partial t}=0
$$

Where

$\rho=$ density of fluid

$\mathrm{U}_{\mathrm{x}}, \mathrm{U}_{\mathrm{y}}, \mathrm{U}_{\mathrm{z}}=$ volumetric velocity in 3 dimension

But for steady state,

$$
\begin{gathered}
\frac{\partial \rho}{\partial t}=0 \\
\frac{\partial}{\partial x}\left(\rho U_{x}\right)+\frac{\partial}{\partial y}\left(\rho U_{y}\right)+\frac{\partial}{\partial z}\left(\rho U_{z}\right)=0
\end{gathered}
$$

The above equation is for three dimensional steady state flows.

Considering flow in one dimension i.e. in the $\mathrm{x}$-direction

$$
\frac{\partial}{\partial x}\left(\rho U_{x}\right)=0
$$

The above holds if there is no mass accumulation Integrating w. r. $\mathrm{t} x$

$$
\rho U_{x}=\text { constant }
$$

If there are of the flow is $A$, then the rate of flow is

$$
\rho A U=\text { constant }
$$

Therefore

$$
\begin{aligned}
\rho_{1} A_{1} U_{1}= & \left.\rho_{2} A_{2} U_{2} \text { (mass rate in }- \text { mass rate out }\right) \\
& M_{\text {in }}-M_{\text {out }}=0 \text { or } M_{\text {in }}=M_{\text {out }}
\end{aligned}
$$

Thus, when there is leak

$$
M_{\text {in }}-M_{\text {out }}=M_{\text {leak }}
$$

\subsection{Leak Localization or Location}

When there is a leak, the pipeline experiencing a leak can be modelled by dividing it into three parts - exact location of leak occurrence, upstream and downstream of the leak, as schematically shown in Figure 3. The exact location of the leak is treated as a singularity point mathematically at which gas leaks out to the surrounding area (i.e., leaks from inside to outside of the pipeline).

Let us consider the diagrams below

Let $Q_{1}$ be the inlet gas flowrate of the no leak case in $\mathrm{ft}^{3} / \mathrm{hr}$ $\mathrm{Q}_{2}$ be the output gas flowrate of the no leak case in $\mathrm{ft}^{3} / \mathrm{hr}$ $Q_{R}$ the recorded flowrate at the output section of the pipeline in $\mathrm{ft}^{3} / \mathrm{hr}$

$P_{R}=$ the recorded output pressure in psi

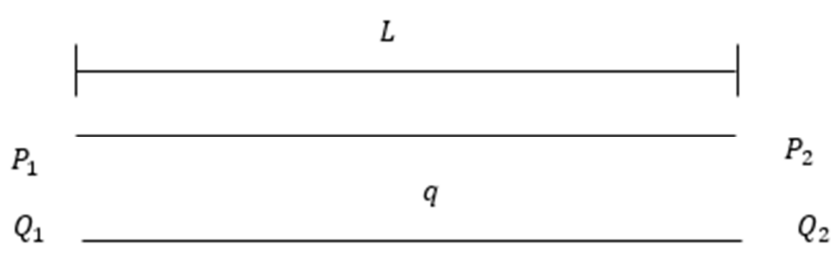

Figure 2. Pipeline Condition for no Leak.

Figure 2 shows a pipeline schematic for gas flow in the absence of leak. From figure 2, it can be seen that the flowrate is same throughout the whole section of the pipeline since flow is in steady state.

$$
Q_{1}=q=Q_{2}
$$

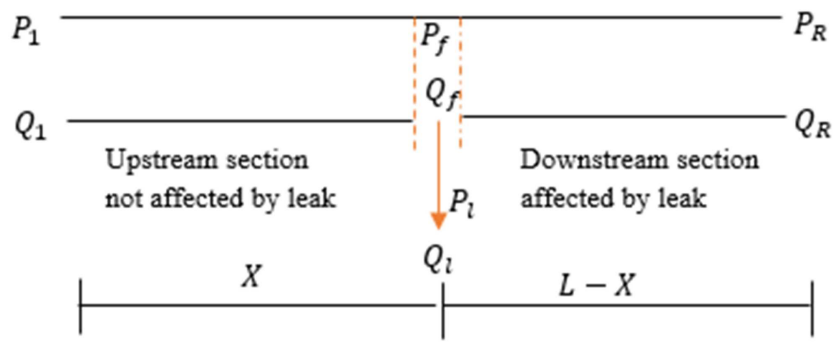

Figure 3. Pipeline Condition for the case of Leak.

Figure 3 shows a pipeline profile in the event of leak, the red arrow represents commodity loss from the pipeline

$$
Q_{R}=Q_{f}
$$

Natural gas flow in horizontal pipeline is modelled by the Weymouth's equation as given below.

$$
q=3.23 \frac{T_{b}}{P_{b}} \sqrt{\frac{1}{f}} \sqrt{\frac{\left(P_{1}{ }^{2}-P_{2}^{2}\right) D^{5}}{\gamma \bar{T} \bar{z} L}}
$$

Where $\mathrm{q}=$ gas flowrate in $\mathrm{ft}^{3} / \mathrm{hr}, \mathrm{T}_{\mathrm{b}}=$ base temperature $\left(60^{\circ} \mathrm{F}\right.$ or $\left.520^{\circ} \mathrm{R}\right), \mathrm{P}_{\mathrm{b}}=$ base pressure $(14.73 \mathrm{psia}), \mathrm{f}=$ Fanning friction factor, $\mathrm{P}_{1}=$ inlet pressure, psia, $\mathrm{P}_{2}=$ outlet pressure, psia, $\gamma=$ gas gravity, $\bar{T}=$ average gas temperature, ${ }^{\circ} \mathrm{R}, \bar{z}=$ gas compressibility factor, $L=$ Length of the pipeline, miles 
The Weymouth equation given above in equ (12) can be adjusted to give

$$
q=3.23 \frac{T_{b}}{P_{b}} \sqrt{\frac{1}{f}}\left(\frac{D^{5}}{\gamma \bar{z} \bar{T} L}\right)^{0.5}\left[\left(P_{1}^{2}-P_{2}^{2}\right)^{0.5}\right]
$$

\subsection{Leak Equation Development}

The general equation for natural gas flow in pipeline is given in compact form as

$$
q=k\left(P_{1}^{2}-P_{2}^{2}\right)^{0.5}
$$

This is similar to the Weymouth's equation given above where $\mathrm{k}$ being the constant of proportionality represents the non-pressure terms in the RHS of the Weymouth's equation. Thus $\mathrm{k}$ is given as follows

$$
k=3.23 \frac{T_{b}}{P_{b}} \sqrt{\frac{1}{f}}\left(\frac{D^{5}}{\gamma \bar{z} \bar{T} L}\right)^{0.5}
$$

When leak occurs in the pipeline, the pipeline can be modelled by taking into consideration two sections of the pipeline. The first section before the leak point is the upstream section which starts from the pipe inlet to the point of leak. The downstream section continues from the point of leak to the outlet of the pipeline. The point of leak is called the midstream; it is not actually a section but a singularity point from which references to the two sections of the pipeline are being made.

\subsubsection{Considering the Upstream Section of the Pipeline}

If we consider the upstream section of the pipeline, the flow equation for gas in this section is given below

$$
Q_{f}=k_{f}\left(P_{1}^{2}-P_{f}^{2}\right)^{0.5}
$$

Where

$Q_{f}=$ the flowrate at the point where leak has occurred $\mathrm{cuft} / \mathrm{hr}$

$P_{f}=$ the pressure midstream of pipeline at the instant just before leak occurs

$k_{f}=$ the constant of proportionality in the leak situation similar to $\mathrm{k}$ above with $\mathrm{L}$ replaced by leak point $(\mathrm{X})$

Equation 14 describes the fluid flow equation in the pipeline in the absence of leak while equation 16 describes the fluid flow in the upstream section of the pipeline when leak has occurred.

Combining equations 14 and 15 and taking ratios

$$
\frac{Q_{f}}{q}=\frac{k_{f}\left(P_{1}{ }^{2}-P_{f}{ }^{2}\right)^{0.5}}{k\left(P_{1}{ }^{2}-P_{2}{ }^{2}\right)^{0.5}}
$$

Factoring out the $\mathrm{k}$ terms the equation becomes

$$
\begin{aligned}
& \frac{k_{f}}{k}=\left(\frac{Q_{f}}{q}\right) \frac{\left(P_{1}{ }^{2}-P_{2}{ }^{2}\right)^{0.5}}{\left(P_{1}{ }^{2}-P_{f}{ }^{2}\right)^{0.5}} \\
& k_{f}=k\left(\frac{Q_{f}}{q}\right)\left(\frac{P_{1}{ }^{2}-P_{2}{ }^{2}}{{P_{1}}^{2}-P_{f}{ }^{2}}\right)^{0.5}
\end{aligned}
$$

Where

$$
k_{f}=3.23 \frac{T_{b}}{P_{b}} \sqrt{\frac{1}{f}}\left(\frac{D^{5}}{\gamma \bar{z} \bar{T} X}\right)^{0.5}
$$

Where $\mathrm{X}$ is the leak location

Substituting the values of $\mathrm{k}$ and $k_{f}$ into the equation yields

$$
\begin{aligned}
& 3.23 \frac{T_{b}}{P_{b}} \sqrt{\frac{1}{f}}\left(\frac{D^{5}}{\gamma \bar{z} \bar{T} X}\right)^{0.5}=3.23 \frac{T_{b}}{P_{b}} \sqrt{\frac{1}{f}}\left(\frac{D^{5}}{\gamma \bar{Z} \bar{T} L}\right)^{0.5}\left(\frac{Q_{f}}{q}\right)\left(\frac{P_{1}{ }^{2}-P_{2}{ }^{2}}{P_{1}{ }^{2}-P_{f}{ }^{2}}\right)^{0.5} \\
& 3.23 \frac{T_{b}}{P_{b}} \sqrt{\frac{1}{f}}\left(\frac{D^{5}}{\gamma \bar{z} \bar{T}}\right)^{0.5}\left(\frac{1}{X}\right)^{0.5}= \\
& 3.23 \frac{T_{b}}{P_{b}} \sqrt{\frac{1}{f}}\left(\frac{D^{5}}{\gamma \bar{z} \bar{T}}\right)^{0.5}\left(\frac{1}{L}\right)^{0.5}\left(\frac{Q_{f}}{q}\right)\left(\frac{P_{1}{ }^{2}-P_{2}{ }^{2}}{P_{1}{ }^{2}-P_{f}{ }^{2}}\right)^{0.5}
\end{aligned}
$$

Eliminating same factors give rise to

$$
\begin{aligned}
\left(\frac{1}{X}\right)^{0.5} & =\left(\frac{1}{L}\right)^{0.5}\left(\frac{Q_{f}}{q}\right)\left(\frac{P_{1}{ }^{2}-P_{2}{ }^{2}}{P_{1}{ }^{2}-P_{f}{ }^{2}}\right)^{0.5} \\
\frac{1}{X^{0.5}} & =\frac{1}{L^{0.5}}\left(\frac{Q_{f}}{q}\right)\left(\frac{P_{1}{ }^{2}-P_{2}{ }^{2}}{{P_{1}{ }^{2}-P_{f}{ }^{2}}^{0.5}}\right.
\end{aligned}
$$

Taking reciprocal of both sides of equation (3.33) yields

$$
X^{0.5}=\left(\frac{q}{Q_{f}}\right) \frac{\left(P_{1}{ }^{2}-P_{f}{ }^{2}\right)^{0.5} L^{0.5}}{\left(P_{1}{ }^{2}-P_{2}{ }^{2}\right)^{0.5}}
$$

There is a presence of negative pressure wave that travels forward and backwards from the leak point. That is to say the negative pressure wave travels along both the upstream and downstream sections of the pipeline. If we consider the upstream section of the pipeline, the negative pressure wave travels counterclockwise in a reverse direction. Thus the effect of this is notice in the flowrate term of equation 25 . The flowrate term reverses because of the effect of negative pressure wave to equation 26

$$
X^{0.5}=\left(\frac{Q_{f}}{q}\right) \frac{\left(P_{1}{ }^{2}-P_{f}^{2}\right)^{0.5} L^{0.5}}{\left(P_{1}{ }^{2}-P_{2}{ }^{2}\right)^{0.5}}
$$

Squaring both sides of the equation gives

$$
X=L\left[\left(\frac{Q_{f}}{q}\right)^{2}\left(\frac{P_{1}{ }^{2}-P_{f}{ }^{2}}{P_{1}{ }^{2}-P_{2}{ }^{2}}\right)\right]
$$

Since the point $\mathrm{X}$ is the leak location and it is determined from the upstream section of the pipeline, we shall denote upstream leak location to be $\mathrm{X}_{1}$

$$
X_{1}=L\left[\left(\frac{Q_{f}}{q}\right)^{2}\left(\frac{P_{1}^{2}-P_{f}^{2}}{P_{1}^{2}-P_{2}^{2}}\right)\right]
$$

\subsubsection{Considering the Downstream Section of the Pipeline}

Considering the downstream section of the pipe. The earlier assumption is that flowrate in upstream section of the pipe is uniform while the flowrate in downstream section is also uniform and equal to the recorded output flowrate, $Q_{R}$ (i.e. from equation 11).

In the downstream section of the pipeline, 


$$
Q_{R}=k_{R}\left(P_{f}^{2}-P_{R}^{2}\right)^{0.5}
$$

Where

$Q_{R}=$ the recorded flowrate at the output section of the pipeline in $\mathrm{ft}^{3} / \mathrm{hr}$

$P_{R}=$ the recorded output pressure in psi

$k_{R}=$ Constant which comprise all the other terms in the Weymouth's equation.

$$
k_{R}=3.23 \frac{T_{b}}{P_{b}} \sqrt{\frac{1}{f}}\left(\frac{D^{5}}{\gamma \bar{z} \bar{T}(L-X)}\right)^{0.5}
$$

Comparing equation 14 with equation 16 we have that

$$
\frac{Q_{R}}{q}=\frac{k_{R}\left(P_{f}^{2}-P_{R}^{2}\right)}{k\left(\Delta P^{2}\right)^{0.5}}
$$

Putting in the values of $k_{R}$ and $k$ the equation becomes

$$
\frac{Q_{R}}{q}=\frac{3.23 \frac{T_{b}}{P_{b}} \sqrt{\frac{1}{f}}\left(\frac{D^{5}}{\gamma \bar{z} \bar{T}(L-X)}\right)^{0.5}\left(P_{f}{ }^{2}-P_{R}{ }^{2}\right)^{0.5}}{3.23 \frac{T_{b}}{P_{b}} \sqrt{\frac{1}{f}}\left(\frac{D^{5}}{\gamma \bar{z} \bar{T} L}\right)^{0.5}\left(P_{1}{ }^{2}-P_{2}{ }^{2}\right)^{0.5}}
$$

Solving the equation above gives

$$
\frac{Q_{R}}{q}=\frac{L^{0.5}\left(P_{f}{ }^{2}-P_{R}{ }^{2}\right)^{0.5}}{(L-X)^{0.5}\left(P_{1}{ }^{2}-P_{2}{ }^{2}\right)^{0.5}}=\left[\frac{L\left(P_{f}{ }^{2}-P_{R}{ }^{2}\right)}{(L-X)\left(P_{1}{ }^{2}-P_{2}{ }^{2}\right)}\right]^{0.5}
$$

Squaring both sides of the equation above gives

$$
\left(\frac{Q_{R}}{q}\right)^{2}=\frac{L\left(P_{f}^{2}-P_{R}^{2}\right)}{(L-X)\left(P_{1}^{2}-P_{2}^{2}\right)}
$$

$$
(L-X)=\left(\frac{q}{Q_{R}}\right)^{2} \frac{L\left(P_{f}^{2}-P_{R}^{2}\right)}{\left(P_{1}^{2}-P_{2}^{2}\right)}
$$

Making X the subject of formula gives

$$
\begin{gathered}
X=L-\left[\left(\frac{q}{Q_{R}}\right)^{2} \frac{L\left(P_{f}{ }^{2}-P_{R}{ }^{2}\right)}{\left(P_{1}{ }^{2}-P_{2}{ }^{2}\right)}\right] \\
X=L\left\{1-\left[\left(\frac{q}{Q_{R}}\right)^{2} \frac{\left(P_{f}{ }^{2}-P_{R}{ }^{2}\right)}{\left(P_{1}{ }^{2}-P_{2}{ }^{2}\right)}\right]\right\}
\end{gathered}
$$

Since the leak location $\mathrm{X}$ here is determine from the downstream section of the pipeline we shall denote it as $X_{2}$

$$
X_{2}=L\left\{1-\left[\left(\frac{q}{Q_{R}}\right)^{2} \frac{\left(P_{f}^{2}-P_{R}^{2}\right)}{\left(P_{1}^{2}-P_{2}^{2}\right)}\right]\right\}
$$

Equation 38 is used to determine the leak distance by considering the flow from the downstream end of the pipe.

\subsection{Model Simulation}

The necessary steps to simulate the model for leak location comprise the data collection, data validation which was done to ascertain the accuracy of the data; actual simulation and confirmation of simulated results with experimental figures.

Matlab software was used to run the simulation to determine the leak location.

The input data for the pipeline operation is given below. The data correspond to leak data gotten from company's pipeline operation. The model developed shall be used to estimate the leak location and volume of leak for each case.

Thus

Table 1. Data Used for Simulations in This Work.

\begin{tabular}{llllllll}
\hline \multirow{2}{*}{ Parametres } & \multicolumn{1}{l}{ Input Values } & & & & \\
\cline { 2 - 7 } & Case 1 & Case 2 & Case 3 & Case 4 & Case 5 & Case 6 & Case 7 \\
\hline Pipeline length (miles) & 150 & 200 & 180 & 150 & 160 & 120 & 150 \\
Pipeline diameter (in.) & 16 & 20 & 12 & 14 & 15.5 & 12.09 & 14 \\
Inlet pressure (psia) & 1020 & 1200 & 1100 & 950 & 1250 & 1000 & 1080 \\
Outlet pressure (psia) & 500 & 550 & 600 & 750 & 800 & 720 & 680 \\
Flowing fluid temp. $\left({ }^{\circ} \mathrm{F}\right)$ & 100 & 100 & 100 & 100 & 80 & 80 & 100 \\
Base temperature. $\left({ }^{\circ} \mathrm{F}\right)$ & 60 & 60 & 60 & 60 & 60 & 60 & 60 \\
Gas deviation factor & 0.9 & 0.95 & 0.92 & 0.92 & 0.85 & 0.88 & 0.95 \\
Gas specific gravity & 0.65 & 0.65 & 0.6 & 0.65 & 0.6 & 0.67 & 0.65 \\
Gas flowrate at inlet (MMscf/hr) & 4.164 & 7.634 & 1.884 & 2.108 & 4.365 & 1.746 & 2.679 \\
Recorded output flowrate during leak (MMscf/hr) & 3.333 & 6 & 1 & 1.8 & 3.88 & 1.4 & 2 \\
Atmospheric pressure (psia) & 14.7 & 14.7 & 14.7 & 14.7 & 14.7 & 14.7 & 14.7 \\
Temperature at standard conditions ( $\left.{ }^{\circ} \mathrm{R}\right)$ & 520 & 520 & 520 & 520 & 520 & 520 & 520 \\
Recorded output pressure during leak (psia) & 603.38 & 745.95 & 966.7 & 751.75 & 671.73 & 678.33 & 755.78 \\
\hline
\end{tabular}

\section{Results}

The results given below show the leak locations and the pressure in the pipeline at the point of leak, calculated from the various input variables from each case give in table 1 above.

Table 2. Results of simulation for various cases.

\begin{tabular}{llll}
\hline Case & Leak Location (Miles) & Leak Location (Km) & Pressure In Pipeline at Leak Point (Pf) \\
\hline Case 1 & 35.05 & 56.39545 & 867.27 \\
Case 2 & 31.78 & 51.13402 & 1071.2 \\
Case 3 & 2.34 & 3.76506 & 1082 \\
Case 4 & 96.56 & 155.365 & 812.83 \\
\hline
\end{tabular}




\subsection{Comparison of Model with Actual Field Results}

The table given below shows the result calculated from the model and the one from the actual field.

Table 3. Table of Comparison of Calculated Results from Model and Actual Measured Result.

\begin{tabular}{|c|c|c|c|c|}
\hline Case & Leak Distance From Model (Km) & Actual Field Results & Absolute Error & \% Error \\
\hline case 1 & 56.39545 & 56.15 & 0.00437 & 0.437133 \\
\hline case 2 & 51.13402 & 50.98 & 0.00302 & 0.302118 \\
\hline case 3 & 3.76506 & 3.78 & 0.003952 & 0.395238 \\
\hline case 4 & 105.293 & 104.9 & 0.00375 & 0.374604 \\
\hline Average error & & & & 0.377273 \\
\hline Maximum error & & & & 0.437133 \\
\hline Standard deviation & & & & 0.056454 \\
\hline
\end{tabular}

The average error gotten from the leak location when compared with field data is $0.377 \%$.

\subsection{Sensitivity Analyses}

For each of the following cases, the pressure profile for the leak and no leak case is given in graphical form.

Case 1

Table 4. Pressure profile data for leak and no leak for case 1.

\begin{tabular}{llll}
\hline No Leak & \multicolumn{3}{c}{ Leak Case } \\
\hline length, L (miles) & Pressure (psi) & length, L (miles) & Pressure (psi) \\
\hline 0 & 1020 & 0 & 1020 \\
20 & 966.9944 & 20 & 966.9944 \\
35.047 & 925.1158 & 35.047 & 867.27 \\
40 & 910.9096 & 150 & 603.38 \\
80 & 786.8371 & & \\
100 & 716.7921 & & \\
120 & 639.1158 & & \\
140 & 550.588 & & \\
150 & 500.486 & & \\
\hline
\end{tabular}

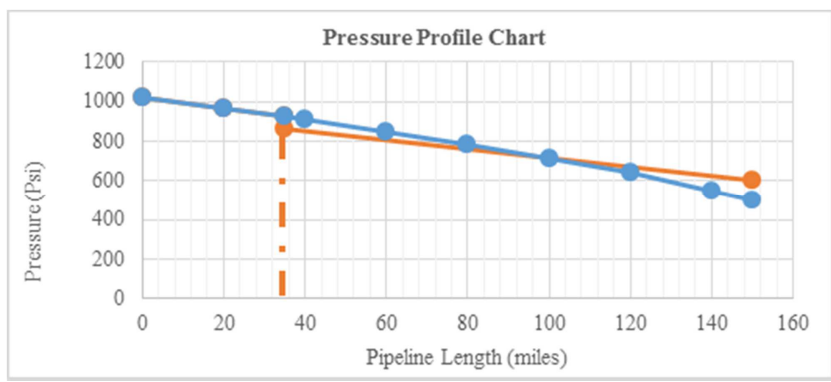

Figure 4. Pressure profile chart showing leak and no leak situations for case

From figure 4 , it can be seen that the leak occurred at 35 miles from the inlet point. The pressure profile for the leak in the event of leak depicts reduction in flowing fluid pressure until a point 100 miles from the pipeline inlet point where the pressure has stabilized and continues to increase with increase in pipe length.

Case 2
Table 5. Pressure profile data for leak and no leak for case 2.

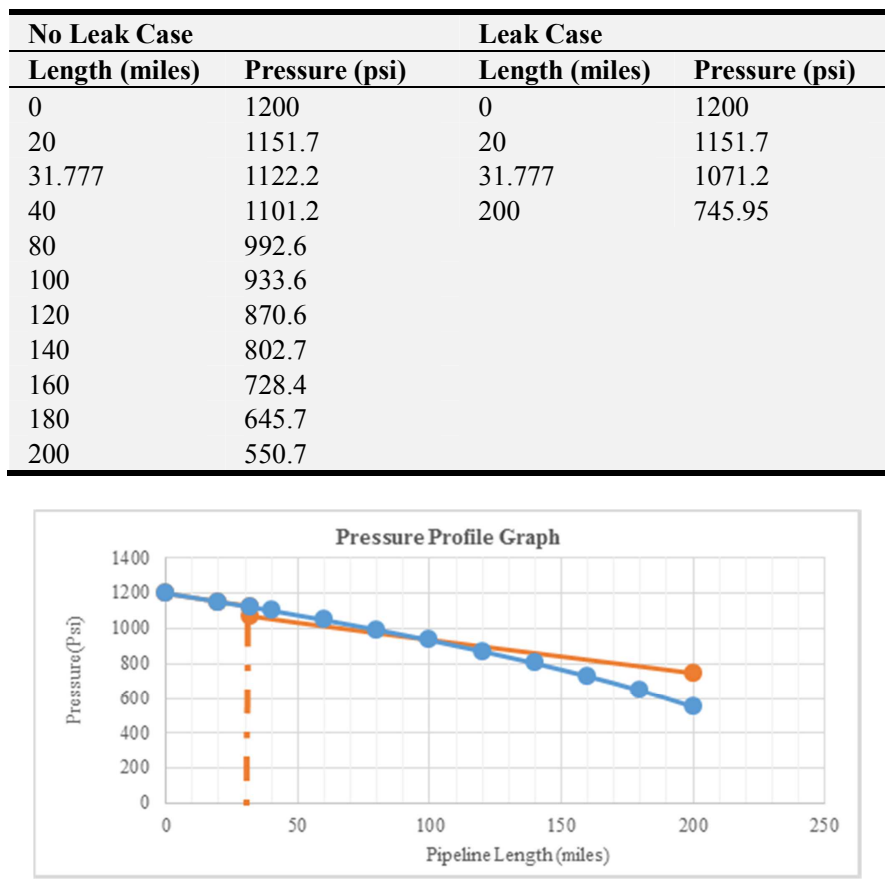

Figure 5. Pressure profile chart showing leak and no leak situations for case 2 .

From figure 5 (For case 2), the leak occurred at 31.78 miles from the inlet point. This gave a sharp drop in the pressure inside the pipeline corresponding to the point of the leak. This pressure reduction decreases to a stabilization point at 100 miles. At this point the pressure in the pipeline in the event of leak is equal to the pressure in the pipeline in the absence of leak at the same location (100miles from inlet).

Case 3

Table 6. Pressure profile data for leak and no leak for case 3.

\begin{tabular}{llll}
\hline No Leak Case & \multicolumn{3}{c}{ Leak Case } \\
\hline Length (miles) & Pressure (Psi) & Length (miles) & Pressure (Psi) \\
\hline 0.2 & 1099.6 & 0.2 & 1099.6 \\
0.5 & 1098.9 & 0.5 & 1098.9 \\
1 & 1097.9 & 1 & 1097.9 \\
2.337 & 1095 & 2.337 & 1082 \\
10 & 1078.3 & & \\
20 & 1056.2 & & \\
\hline
\end{tabular}




\begin{tabular}{llll}
\hline No Leak Case & & Leak Case & \\
\hline Length (miles) & Pressure (Psi) & Length (miles) & Pressure (Psi) \\
\hline 40 & 1010.6 & & \\
60 & 962.8 & & \\
80 & 912.5 & & \\
100 & 859.2 & & \\
120 & 802.4 & & \\
140 & 741.3 & & \\
160 & 674.6 & & \\
180 & 600.6 & & \\
\hline
\end{tabular}

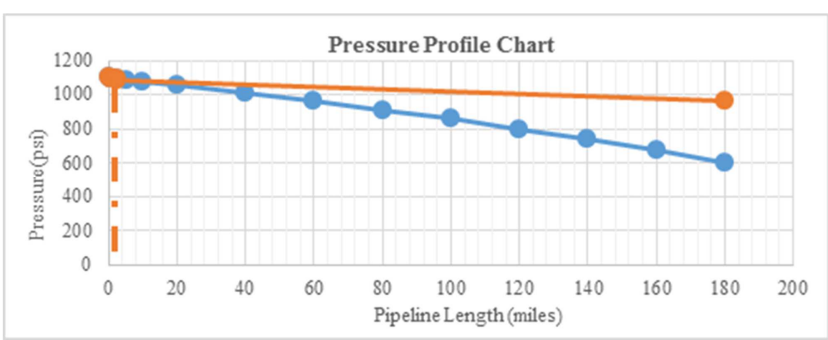

Figure 6. Pressure profile chart showing leak and no leak situations for case

From figure 6 (case 3 ), the leak occurred at an early point. The leak location is at 2.34 miles from the inlet point. The pressure stabilized quickly since the leak occurred at the early point of the pipeline. The stabilization point of the leak pressure profile with the no-leak pressure profile as seen from figure 4 is at 20 miles from the inlet point.

Case 4

Table 7. Pressure profile data for leak and no leak for case 4.

\begin{tabular}{llll}
\hline $\begin{array}{l}\text { No Leak Case } \\
\text { Distance } \\
\text { (miles) }\end{array}$ & Pressure (Psi) & Length (miles) & Pressure (Psi) \\
\hline 0 & 950 & 0 & 950 \\
10 & 938.0023 & 10 & 938.0023 \\
20 & 925.8492 & 20 & 925.8492 \\
40 & 901.0514 & 40 & 901.0514 \\
60 & 875.5515 & 60 & 875.5515 \\
80 & 849.2863 & 80 & 849.2863 \\
96.56 & 826.9075 & 96.56 & 812.83 \\
120 & 794.1541 & 150 & 742.33 \\
140 & 765.0997 & & \\
150 & 750.1506 & & \\
\hline
\end{tabular}

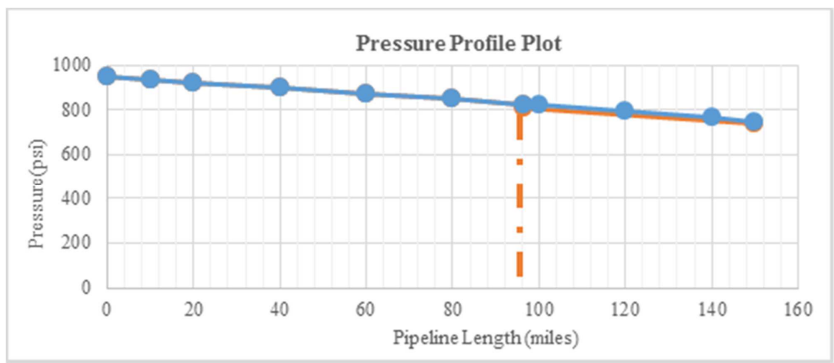

Figure 7. Pressure profile chart showing leak and no leak situations for case 4.

From figure 7 (case 4), the leak location occurred at 96.56 miles from the inlet point while the stabilization point of the no- leak pressure profile with the leak pressure profile is at the downstream i.e. at 150 miles as seen from the figure 7 .
Table 8. Summary of Leak Location Results.

\begin{tabular}{llll}
\hline Case & $\begin{array}{l}\text { Pipeline length } \\
\text { (miles), } \mathbf{L}\end{array}$ & $\begin{array}{l}\text { Leak Location } \\
\text { (Miles), } \mathbf{X}_{\mathbf{1}}\end{array}$ & $\begin{array}{l}\text { Leak Location } \\
\text { (Miles), } \mathbf{X}_{\mathbf{2}}\end{array}$ \\
\hline Case 1 & 150 & 35.05 & 35.04 \\
Case 2 & 200 & 31.78 & 31.77 \\
Case 3 & 180 & 2.34 & 2.34 \\
Case 4 & 150 & 96.56 & 96.56 \\
Case 5 & 160 & 139.5 & 139.51 \\
Case 6 & 120 & 86.48 & 86.48 \\
Case 7 & 150 & 34.94 & 34.94 \\
\hline
\end{tabular}

\section{Discussions}

1. Case 1: From the table 2 above it can be seen that the leak location calculated occurred at a distance of $56.395 \mathrm{~km}$ ( 35.05 miles) from pipeline inlet point and pressure in the pipeline at the leak point of 867.27 psia. Pressure in the pipeline at the leak point gave a reasonable prediction by the model since the input pressure and output pressure for case 1 are 1020 psi and 500 psi respectively. It is expected that the leak point pressure be lower than the input pressure and higher than the output pressure.

2. Case 2: From table 2 above case 2 predicts the leak location to be at $51.13 \mathrm{~km}$ ( 31.78 miles) and pressure in the pipeline at the leak point is 1071.2psi. Also the pressure in the pipeline at the leak point is between the input pressure (1200psi) and the output pressure for no leak (550 psi).

3. Case 3: From table 2 above, the model estimated the leak location for the case 3 to be at $3.77 \mathrm{~km}$ (2.34 miles) and pressure in the pipeline at the leak point is $1082 \mathrm{psi}$. The initial input and output pressures for the no-leak situation is given as $1100 \mathrm{psi}$ and $600 \mathrm{psi}$. The pressure in the pipeline at the leak point as expected falls between the initial input and output pressures.

4. Case 4: From table 2 above, the leak location for case 4 was calculated to be at $155.365 \mathrm{~km}$ from the inlet point. The leak point pressure is calculated to be $812.83 \mathrm{psi}$. The input and output pressure for the initial no-leak situation are 950psi and 750psi respectively. The leak point pressure also falls between the input and output pressure for the no-leak case.

5. From table 3 , the average percentage error from the proposed model is $0.377 \%$. This is lower than the model proposed by Boaz et al. (2014) with average error of $3.575 \%$ which was acceptable for leak location. Thus the proposed model gives a more accurate estimation of the leak location in the event of leak in natural gas pipeline.

\section{Conclusions}

Mathematical models have been developed for leak location in natural gas pipeline. The models developed were in two-fold, the upstream and the downstream leak location models. The models instantaneously estimate the location of leak upon occurrence. Either of the model can be applied 
without necessarily applying the two for leak location. The models have been proven to yield the same result and the results showed high accuracy when compared with data from actual leak locations from operating companies with only an average error of $0.377 \%$. The model relies highly on the accuracy of the input data which are hydraulic parametres of the operating pipeline. This work is recommended for instant leak location in gas pipelines especially when physical inspection methods proves costly and would interrupt normal pipeline operations.

\section{References}

[1] Nicholas, E., Carpenter, P., Henrie, M., Hung, D., Kundert, C. (2017). A New Approach to Testing Performance of a Pipeline Leak Detection System. Paper prepared for presentation at the PSIG Annual Meeting held in Atlanta, Georgia, USA.

[2] Kegang Ling, Guoqing Han, X. N, Chunming Xu, Jun He, Peng Pei, and Jun Ge. (2015): A New Method for Leak Detection in Gas Pipelines, Paper (SPE 1891568) accepted for presentation at the SPE/AAPG/SEG Unconventional Resources Technology Conference, Denver.

[3] Baltazar, S. T. and Azevedo Perdicoúlis, T-P and Lopes dos Santos, P. (2016). Quadripole Models for Simulation and Leak Detection on Gas Pipelines. Paper prepared for presentation at the PSIG Annual Meeting held in Vancouver, British Columbia.

[4] Qian, D. and Fox, P. H. and See, B. L., (2015). Accurate Natural Gas Load Hourly Forecasting Using ANN Model Trained with Multiple Parameters'. 46th PSIG Annual Meeting, New Orleans, LA, USA.

[5] Reddy, H. P., Narasimhan, S., and Bhallamudi, S. M. (2006): Simulation and State Estimation of Transient Flow in Gas Pipeline Networks Using Transfer Function Model. Ind. Eng. Chem. Res. 45 (11): 3853-3863.

[6] Wang, S. and Carroll, J. J. 2007. Leak Detection for Gas and Liquid Pipelines by Online Modeling. SPE Proj Fac \& Const 2 (2): 1-9. SPE- 104133-PA.
[7] Gajbhiye, R. N. and Kam, S. I. (2008). Leak Detection in Subsea Pipeline: A Mechanistic Modeling Approach with Fixed Pressure Boundaries. Presented at the Offshore Technology Conference, Houston, 5-8 May. OTC-19347-MS.

[8] Elliott, J., Fletcher, R., and Wrigglesworth, M. (2008): Seeking the Hidden Threat: Applications of a New Approach in Pipeline Leak Detection. Presented at the Abu Dhabi International Petroleum Exhibition and Conference, Abu Dhabi, 3-6 November. SPE-118070-MS.

[9] Hauge, E., Aamo, O. M., and Godhavn, J.-M. (2009): ModelBased Monitoring and Leak Detection in Oil and Gas Pipelines. SPE Proj Fac \& Const 4 (3): 53-60. SPE-114218PA.

[10] Schlumberger. (2014). OLGA Dynamic Multiphase Flow Simulator

http://www.software.slb.com/products/foundation/Pages/olga. aspx.

[11] Ben-mansour, R., Habib, M. A., Khalifa, A., Youcef-Toumi, K and Chatzigeorgiou, D. (2012). Computational Fluid Dynamics Simulation of Small Leaks in Water Pipeline for Direct Leak Pressure Transduction. Computers \& Fluids, 57, 110-123.

[12] Balda Rivas, K. V. and Civan, F. (2013): Application of Mass Balance and Transient Flow Modeling for Leak Detection in Liquid Pipelines. Presented at the SPE Production and Operations Symposium, Oklahoma City, Oklahoma, USA, 23-26 March. SPE-164520-MS.

[13] Zhu, H., Lin, P. \& Pen, Q. (2014). A CFD (Computational Fluid Dynamics) Simulation for Oil Leakage from Damaged Submarine Pipeline, Energy, 64, 887-899.

[14] Hanmer, G., Mora, V., Fábio C. G., Sergio L. (2018). Modelling of Rapid Transients in Natural Gas Pipelines. Paper prepared for presentation at the PSIG Annual Meeting held in Deer Valley, Utah.

[15] Thodi, P., Paulin, M., Forester, L., Burke, J., Lanan, G. (2014). Arctic Pipeline Leak Detection using Fibre Optic Cable Distributed Sensing System. In OTC arctic Technology Conference. Offshore Technology Conference, Houstin, Texas. 